Relations industrielles

Industrial Relations

\title{
Gould IV, W.B., A Primer on American Labor Law
}

\section{Pierre Verge}

Volume 49, numéro 3, 1994

URI : https://id.erudit.org/iderudit/050964ar

DOI : https://doi.org/10.7202/050964ar

Aller au sommaire du numéro

Éditeur(s)

Département des relations industrielles de l'Université Laval

ISSN

0034-379X (imprimé)

1703-8138 (numérique)

Découvrir la revue

Citer ce compte rendu

Verge, P. (1994). Compte rendu de [Gould IV, W.B., A Primer on American Labor Law]. Relations industrielles / Industrial Relations, 49(3), 608-609.

https://doi.org/10.7202/050964ar

Tous droits réservés @ C Département des relations industrielles de l'Université Laval, 1994
Ce document est protégé par la loi sur le droit d'auteur. L'utilisation des services d'Érudit (y compris la reproduction) est assujettie à sa politique d'utilisation que vous pouvez consulter en ligne.

https://apropos.erudit.org/fr/usagers/politique-dutilisation/ 
It would be useful to know the eventual outcome of the employee suit against Navistar and whether Hammond's restrictions on tax-abatements has served the city well.

Despite these shortcomings, this modest volume will be useful both to show how corporate strategies look from the shop floor and how, through a combination of perseverance, excellent strategy, and good fortune, some of those on the shop floor have successfully challenged the dominance of business power in our society.

Dale BeLMan

Economic Policy Institute

Washington, DC

A Primer on American Labor Law, by W.B. Gould IV, $3^{e}$ édition, Cambridge, MrT Press, 1993, 326 p., ISBN 0-262-07149-5 (reliure toile), ISBN 0-262-57099-8 (reliure cartonnée).

Il convient de s'arrêter à cette troisième édition de l'ouvrage originaire, déjà recensé [voir (1983) 38 Relations industrielles 180]. Il s'agit toujours, en effet, comme nous le constations alors, de l'une des rares véritables synthèses du droit du travail américain, au milieu d'une prolifération d'écrits à caractère technique. Or, le besoin de connaissance de ce droit de la première puissance économique mondiale ne peut que croître, en particulier au Canada, compte tenu de l'entrée en vigueur, en janvier dernier, de l'Accord nord-américain de coopération dans le domaine du travail, complément de l'ALENA, accord ayant notamment pour objectif d'assurer une « meilleure compréhension mutuelle des lois régissant le travail sur le territoire de chacune des parties ».

Le contenu général de cette troisième édition correspond substantiellement, sous réserve d'une certaine amplification, à celui du texte initial, dont il réitère d'ailleurs la structure. Axé primordialement sur le droit des rapports collectifs du travail, on y présente avec une heureuse insistance les antécédents historiques du régime actuel issu du New Deal, avant d'exposer les aspects prédominants de ce dernier: désignation du représentant collectif, les différentes pratiques déloyales en matière de représentation et de négociation collectives, l'appréhension juridique de celle-ci, y compris la licéité du recours aux différents moyens de pression, le régime de l'arbitrage de grief de convention collective, l'obligation de représentation égale du représentant collectif et l'intervention législative en matière de démocratie syndicale. Les deux derniers chapitres sont toujours consacrés au particularisme du secteur public, de même qu'à la législation normative et d'intérêt public.

Toute cette matière fait naturellement l'objet d'une mise à jour. On y traite ainsi notamment de la jurisprudence récente du NLRB (affaire Électromation Inc.) relative à la légalité de comités d'entreprise (p. 47), de la tentative avortée d'introduire des dispositions anti-briseurs de grève dans la loi fédérale, de l'entreprise de démocratisation des Teamsters en 1991 (p. 168)... Ceci dit, les innovations les plus marquantes ont trait à la législation directement protectrice de l'ensemble des salariés : obligation de préavis de fermeture de l'établissement en 1988 (p. 115), congé parental et de maladie de 1993 (p. 194), interdiction de discrimination fondée sur le handicap en 1992 (p. 200), multiplicité dans les lois de différents états des restrictions au licenciement ad nutum 
(p. 206)... L'évolution jurisprudentielle probablement la plus significative est du même ordre, qu'il s'agisse, en matière de discrimination sexuelle, du traitement du harcèlement sexuel et des disparités salariales indues (p. 195-196), ou encore, de la discrimination mettant en cause l'orientation sexuelle (p. 198). À cet égard, la prédiction de l'auteur, il y a plus d'une dizaine d'années, d'une certaine croissance de la protection juridique générale de la personne au travail, se révèle juste.

Ce même auteur n'hésite pas d'ailleurs à se montrer critique à l'occasion à l'endroit de diverses solutions jurisprudentielles, qu'il s'agisse en particulier du sort des grévistes remplacés (p. 99), de la distinction entre sujets obligatoires et permissifs de négociation collective (p. 109). Il s'en prend également à l'abstentionnisme d'arbitres de grief lorsqu'il s'agit de l'application de l'interdiction légale de discrimination à l'endroit de l'employeur ou du syndicat (p. 139), de même qu'à certains jugements en la matière, par exemple cet arrêt de la Cour d'appel du cinquième circuit permettant à un employeur d'interdire à des hispanophones de parler entre eux leur langue en présence de clients de langue anglaise de l'entreprise (p. 195).

Globalement, l'auteur continue en conclusion de prédire l'excroissance de la législation directement protectrice et d'ordre public. Ceci pourra, dans une certaine mesure, compenser le déclin marqué, présentement observable, de l'action syndicale traditionnelle. Certes, à ce dernier sujet, certains syndicats s'insèreront-ils dans des formules innovatrices de participation; mais la problématique générale d'une éventuelle redéfinition de l'encadrement juridique de la représentation des salariés aux États-Unis reste en plan. L'auteur, bien conscient de la difficulté (voir sa préface de la présente édition), ne peut l'esquiver en y signalant les succès particuliers de la négociation collective dans le monde du baseball...

Même si nous devons ainsi rester sur notre faim quant à l'orientation future de la représentation des salariés outre-frontière, nous continuons de trouver dans le précis du professeur Gould cette brillante et parfois incisive synthèse des aspects significatifs du droit du travail américain.

Pierre Verge

Université Laval

New Perspectives on Industrial Disputes, by David Metcalf and Simon Milner (ed.), London, Routledge, 1993, 262 p., ISBN 0-415-09151-9.

This edited volume arises out of a conference held at the London School of Economics in 1992. Many conference based books give the impression that participants were primarily attracted by the opportunity to visit a new city, with many of the papers having been written on the plane. It is pleasing to say that this particular volume does not fall into this category. Instead what we have here is a book very much based on contributions from individuals actively involved in various strands of research concerning various aspects of industrial disputes.

The book consists of eleven substantive chapters. The first is a scene-setting one by the editors which highlights the major themes addressed in the individual chapters, 